\title{
NOTAS PARA LA LECTURA DE ÁLBUMES SIN PALABRAS. DISCURSO NO FICCIONAL Y VIAJE MIGRATORIO ${ }^{1}$
}

\author{
NOTES ON READING WORDLESS PICTURE BOOKS. \\ NON-FICTIONAL DISCOURSE AND MIGRATORY JOURNEY \\ NOTAS PARA LEITURA DE ÁLBUNS SEM PALAVRAS. \\ DISCURSO NÃO FICCIONAL E VIAGEM MIGRATÓRIA
}

\author{
María Jesús Colón Castillo \\ Universidad de Zaragoza, España \\ https://orcid.org/0000-0003-0942-1840 \\ mjcolon@unizar.es
}

Recibido: 23/04/2021 Revisado: 15/05/2021 Aceptado:15/05/2021 Publicado: 01/07/2021

Resumen: Los álbumes sin palabras se caracterizan por una concepción visual y multimodal en el contexto de la complejidad de la literatura infantil posmoderna. Su lectura desafía a los lectores infantiles y supone un reto para los mediadores en el desarrollo de la alfabetización visual y la educación artística en contextos educativos. El estudio que se presenta pretende aportar unas orientaciones para la lectura a partir del análisis de una selección de obras que abordan el fenómeno migratorio desde la experiencia del viaje. Estos libros suelen ser analizados desde enfoques sociales e ideológicos a los que se desea sumar una nueva perspectiva, con el objetivo de propiciar lecturas multirreferenciales, críticas y reflexivas. El análisis muestra cómo el discurso no ficcional se encuentra latente bajo un relato aparentemente ficcional. Este discurso se manifiesta como estrategia constructiva a través de personajes colectivos, lugares comunes, voces de autoría o símbolos que abstraen una mirada universal y colectiva de la experiencia migratoria, lo que explicaría, en parte, la imagen homogénea que se tiende a transmitir de las personas inmigrantes o refugiadas en estas obras. El resultado son álbumes próximos al género documental en los que la ficción es un soporte que implica al lector.

Palabras claves: Álbum sin palabras; No ficción; Lectura multimodal; Alfabetización visual; Migraciones.

\begin{abstract}
One of the most distinguishing features of wordless picture books is a visual and multimodal conception within the context of the complexity of postmodern children's literature. Reading them challenges child readers and also mediators in the development of visual literacy and art education in educational contexts. This study aims to provide guidance for reading based on the analysis of works that address the migratory phenomenon from the experience of the journey. These books are usually analysed from social and ideological approaches but this work aims to contribute a new perspective in order to prompt multireferential, critical and reflective readings. The analysis shows how non-fictional discourse is latent behind a seemingly fictional account. This discourse is revealed as a constructive strategy through collective characters, common places, authorship voices or symbols that reflect a universal and collective view of the migratory experience, which, in turn, would explain the uniform portrait of migrants and refugees in these works. As a result, these picture books are closer to the documentary genre in which fiction is a foundation that involves the reader.
\end{abstract}

Keywords: Wordless picture books; Non-fiction; Multimodal reading; Visual literacy; Migrations. 
Resumo: Os álbuns sem palavras são caracterizados por uma concepção visual e multimodal no contexto da complexidade da literatura infantil pós-moderna. A sua leitura desafia os jovens leitores e também os mediadores no desenvolvimento da literária visual e da educação artística em contextos educativos. $\mathrm{O}$ estudo que se apresenta visa fornecer algumas orientações para a leitura a partir da análise de uma seleção de obras que abordam o fenómeno migratório a partir da experiência da viagem. Esses livros são geralmente analisados a partir de abordagens sociais e ideológicas às quais se deseja adicionar uma nova perspetiva, com o objetivo de promover leituras multirreferenciais, críticas e reflexivas. A análise mostra como o discurso não ficcional está latente num relato aparentemente ficcional. Este discurso manifesta-se como estratégia construtiva através de personagens coletivas, lugares-comuns, vozes de autoria ou símbolos que refletem uma visão universal e coletiva da experiência migratória, o que explicaria, em parte, a imagem homogénea que tende a ser transmitida dos imigrantes ou refugiada nessas obras. $\mathrm{O}$ resultado são álbuns próximos do género documental em que a ficção é um suporte que envolve o leitor.

Palavras-chave: Álbum sem palavras; Não ficção; Leitura multimodal; Alfabetização visual; Migrações

Cómo citar este artículo: Colón, $\mathrm{M}^{\mathrm{a}}$. J. (2021). Notas para la lectura de álbumes sin palabras. Discurso no ficcional y viaje migratorio. Hachetetepé. Revista científica en Educación y Comunicación, (23), 1-15. https://doi.org/10.25267/Hachetetepe.2021.i23.2201

\section{INTRODUCCIÓN}

\section{1.Álbum posmoderno y álbum sin palabras}

Según Lewis (2001), en el ámbito de la literatura infantil, el álbum sin palabras surgió en la década de 1970 como una variedad del álbum posmoderno, por lo que ambos estarían conectados por una red de semejanzas. La experimentalidad, la intertextualidad o la metaficción se muestran, como algunos de sus rasgos más frecuentes (Sipe y Pantaleo, 2008; Tabernero-Sala, 2013). Sin embargo, aunque resulte contradictorio, el álbum sin palabras carece, en principio, de uno de los dos discursos que fundamentan el concepto de álbum (Bosch, 2015). Es decir, desde los primeros estudios sobre el género, la especial interdependencia entre el texto y la imagen se ha estimado como un aspecto definitorio del álbum (Bader, 1976; Nodelman, 2000, 2010; entre otros muchos). Frente a esta concepción, la ausencia de un texto esencial (Genette, 2001) en relación próxima con las imágenes (Lewis, 2001) posiciona a los álbumes sin palabras en el extremo de la categoría visual (Nikolajeva y Scott, 2006). Esta ubicación fronteriza trasciende los límites de lo literario (Tabernero-Sala, 2005), cuestión que ha propiciado la defensa de la literariedad del álbum sin palabras (Ducrot, 2014) y de un concepto más amplio y flexible del hecho literario (Costa y Ramos, 2021).

En este sentido, la experiencia de lectura se muestra condicionada por la naturaleza visual del álbum sin palabras Las ilustraciones secuenciadas se conforman como la voz principal y no cuentan con un texto narrativo próximo (Lewis, 2001), desaparece su función de anclaje (Serafini, 2014; Van der Linden, 2015) y también la capacidad de las palabras para expresar la subjetividad de los personajes, sus sentimientos o pensamientos, lo que les sucedió en el pasado o sus proyecciones de futuro (Nodelman, 2000). La polisemia y la elipsis se intensifican, por lo que entran en funcionamiento otros mecanismos de sujeción (Lartitegui, 2014). Como señala Van der Linden (2015, p. 70), un álbum sin palabras no es un álbum al que se le ha eliminado el texto, "su funcionamiento pone de relieve una mecánica delicada". Los autores juegan con la 
elocuencia de las ilustraciones, con su mayor o menor ambigüedad (Lysaker, 2019), con los vacíos de información y, paradójicamente, también con las palabras. De hecho, en un álbum sin palabras suelen encontrarse textos significativos subyacentes (Bosch, 2015). En consecuencia, se refuerza la intensidad de las palabras y la información que aportan resulta especialmente valiosa en la experiencia de lectura.

\subsection{La lectura multimodal en el contexto educativo}

Para Kümmerling-Meibauer (2015), la literatura infantil ilustrada se caracteriza por varias tendencias, como la materialidad, la hibridación, la metaficción, el multilingüismo o la digitalización. Aunque se trata de cambios que se observan desde las décadas de los 80 y 90, en la actualidad tienden a articularse en composiciones multimodales que desafían a los lectores infantiles, especialmente los álbumes sin palabras, por su mayor ambigüedad (Serafini, 2014) y por el extrañamiento que la imagen sin anclaje tiende a generar (Lartitegui, 2014). Estos receptores infantiles, familiarizados con las pantallas y con los entornos digitales (Tabernero-Sala, 2016: Tabernero-Sala et al., 2020), se encuentran carentes de estrategias para interpretar la complejidad de los textos multimodales, pues, como señala Eisner (2020), el ver de la vida cotidiana es muy diferente de la mirada y de la atención que requieren las representaciones visuales, una mirada observadora, reflexiva y formada en la que interviene la educación artística.

La lectura multimodal y la alfabetización visual se convierten así en un reto para los docentes, al que se suma la necesidad de motivar hábitos lectores estables ante la emergencia que se desprende de los resultados de estudios empíricos recientes (RomeroOliva et al., 2019; Trigo Ibáñez et al., 2020). En la actual sociedad de la información, los programas educativos deberían capacitar al alumnado para leer, interpretar y crear textos multimodales desde una perspectiva crítica (Tomasi, 2014). A este respecto, las narrativas visuales, basadas en la imagen secuencial, constituyen un recurso educativo de interés para activar la imaginación y el pensamiento crítico, pues permiten "hacer comunicable lo inexplicable" (Grande López, 2018, p. 73). Como señalan Romero-Oliva et al. (2019), el carácter intertextual e hipertextual de los formatos multimodales supone igualmente una oportunidad para el desarrollo de la competencia lectora y literaria de los estudiantes, al interconectar diferentes modalidades textuales por las que los lectores navegan.

\section{DISEÑO DEL ESTUDIO}

\subsection{Objetivo del análisis: el discurso no ficcional}

Los resultados de las investigaciones sobre la recepción del álbum sin palabras confirman su adecuación en el contexto escolar, especialmente por la estimulación que su lectura provoca en las estrategias cognitivas, emocionales y estéticas, y en la competencia comunicativa del alumnado (Colón y Tabernero-Sala, 2018; Iordanaki, 2017; Lysaker, 2019; Mantei y Kervin, 2015, entre otros). Sin embargo, no se trata de libros habituales en el entorno educativo, pues, según la investigación de Skubic y Podobnik (2018), los docentes no los utilizan por el desconocimiento de estrategias que faciliten su inclusión en las aulas. Asimismo, otros trabajos insisten en la necesidad de la formación de los mediadores en relación con la literatura infantil ilustrada, dada la complejidad del álbum posmoderno (Tabernero-Sala, 2013; Valencia-Leguizamón y Real, 2019). Desde estos presupuestos, se estiman de interés los trabajos que han incidido en el análisis del discurso del álbum sin palabras, como los de Bosch (2015), Beckett (2012), Terrusi (2017) y Lartitegui (2014), al contribuir a la comprensión del formato. 
Del mismo modo, con este estudio, se pretenden aportar unas orientaciones que faciliten la interpretación del álbum sin palabras. Para ello, se ha centrado el objetivo en un aspecto escasamente estudiado, el discurso no ficcional del álbum sin palabras. En los últimos años, los libros de no ficción están experimentado un enorme impulso editorial (Lartitegui, 2018; Sampériz et al., 2021), también entre los álbumes sin palabras, aunque la finalidad documental, informativa, conceptual o filosófica siempre ha estado presente en su trayectoria. Así, en la catalogación realizada por Bosch (2015), la autora denomina como álbum narrativo documental a las obras en las que interesa más mostrar que contar, en las que los espacios cobran más importancia que los personajes, en las que se explican actividades humanas desde una perspectiva genérica o se estimula la reflexión conceptual de forma narrativa. Actualmente, se observa esta tendencia igualmente en publicaciones de álbumes sin palabras aparentemente ficcionales, obras en las que la ficción y la no ficción están presentes, de manera que la ficción puede ser una estrategia discursiva para presentar los contenidos no ficcionales e hilvanar la secuencia ilustrada con la cooperación de la elipsis entre páginas, lo que Sampériz et al. (2021, p. 83) denominan "la elipsis ficcional en el paso de página".

\subsection{Selección del corpus: el viaje migratorio}

Desde que, en 2006, Shaun Tan publicase su novela gráfica Emigrantes hasta el reciente éxito del álbum sin palabras Migrantes (2019) de Isa Watanabe, parece que el viaje migratorio, siendo uno de los temas frecuentes en el álbum, se suele asociar con estos libros. Esta conexión se debe igualmente a la repercusión de proyectos internaciones como la creación de una biblioteca en Lampedusa para niñas y niños refugiados y locales (Zizioli, 2017). La biblioteca se dotó con álbumes sin palabras, por el carácter universal que se atribuye a la imagen y su capacidad de superar barreras lingüísticas. Desde entonces, el programa de IBBY Italia se ha ampliado con exposiciones de libros, listas de honor e investigaciones en torno al álbum sin palabras. Por otra parte, el proyecto de investigación Visual Journeys, dirigido por Evelyn Arizpe (Arizpe et al., 2015), indagó en contextos educativos de varios países sobre la experiencia de lectura de la obra Emigrantes. Según los resultados en este proyecto, los participantes mostraron empatía con las vivencias de los personajes y con las dificultades socioeconómicas y políticas a las que se enfrentan las personas migrantes, además, establecieron vínculos con sus propias experiencias personales. En la misma línea de Arizpe, Nel (2018) considera que el arte y la literatura infantil ofrecen la posibilidad de amplificar la voz de las personas migrantes y refugiadas. El autor defiende así el fomento de una literatura que abogue por los derechos humanos y por la construcción de sociedades libres e igualitarias.

Por su parte, Pesonen (2020) se muestra más crítica con esta literatura. La autora analizó las estrategias utilizadas para dar voz a las personas migrantes y refugiadas en el álbum sin palabras finlandés Meidän piti lähteä [2018] de Sanna Pelliccioni. En su estudio, Pesonen (2020) concede a la literatura un valor pedagógico, atribuye un reconocimiento simbólico a las narrativas en las que se representan grupos minoritarios y considera que, en ocasiones, la imagen difundida ha sido estereotipada, discriminatoria o racista. Así, se pregunta cómo un libro sin palabras, en el que la voz de los personajes está silenciada, puede representar la experiencia de las personas migrantes y refugiadas. Cuando explica las claves de la obra de Pelliccioni, se detiene en la oposición generada entre "nosotros y ellos", propia de los discursos que tratan de reflejar al "otro". Según la autora, incluso las obras que desean transmitir una imagen positiva y favorecer la empatía 
de la sociedad hegemónica pueden acabar reforzando estereotipos y una idea homogénea de las personas migrantes. Además, aunque considera que la falta de texto propiciaría la reflexión de los lectores, en su opinión, también podría predisponer a la reafirmación de estereotipos previos. En este sentido, Pesonen (2020) valora el papel de los mediadores como primordial en la propuesta de lecturas más críticas, capaces de cuestionar los discursos segregacionistas.

A partir del interés educativo concedido a los álbumes sin palabras que representan el viaje migratorio y valorando la importancia del mediador y de su formación en favor de lecturas reflexivas y críticas, se propone la aproximación a una muestra de publicaciones en las que se representa el viaje - en su mayoría, el viaje migratorio- que han sido premiadas y reconocidas en el panorama editorial de los últimos años. Como se ha indicado, el enfoque del análisis se centra en el discurso no ficcional que acompaña a estas obras como clave de interpretación, en tanto que podría explicar algunas de las consideraciones que realiza Pesonen (2020) desde una perspectiva distinta. Los títulos seleccionados han sido los siguientes -Figura 1-:

- Emigrantes de Shaun Tan, publicado en Australia, en 2006, con el título original The Arrival, y en España, en 2007, por Barbara Fiore.

- Migrando de Mariana Chiesa Mateos, publicado en Italia, en 2010, por la editorial Orecchio Acerbo.

- Orizzonti de Paola Formica, publicado en Italia, en 2015, por la editorial Carthusia.

- Migrantes de Issa Watanabe, publicado, en 2019, por Libros del Zorro Rojo.

- La valigia de Angelo Ruta, publicado en 2019 por la editorial Carthusia.

- La Travesía de Peter Van den Enden, publicado en los Países Bajos, en 2019, y en España, en 2020, por Libros del Zorro Rojo. 
Figura 1

Cubiertas de las obras seleccionadas
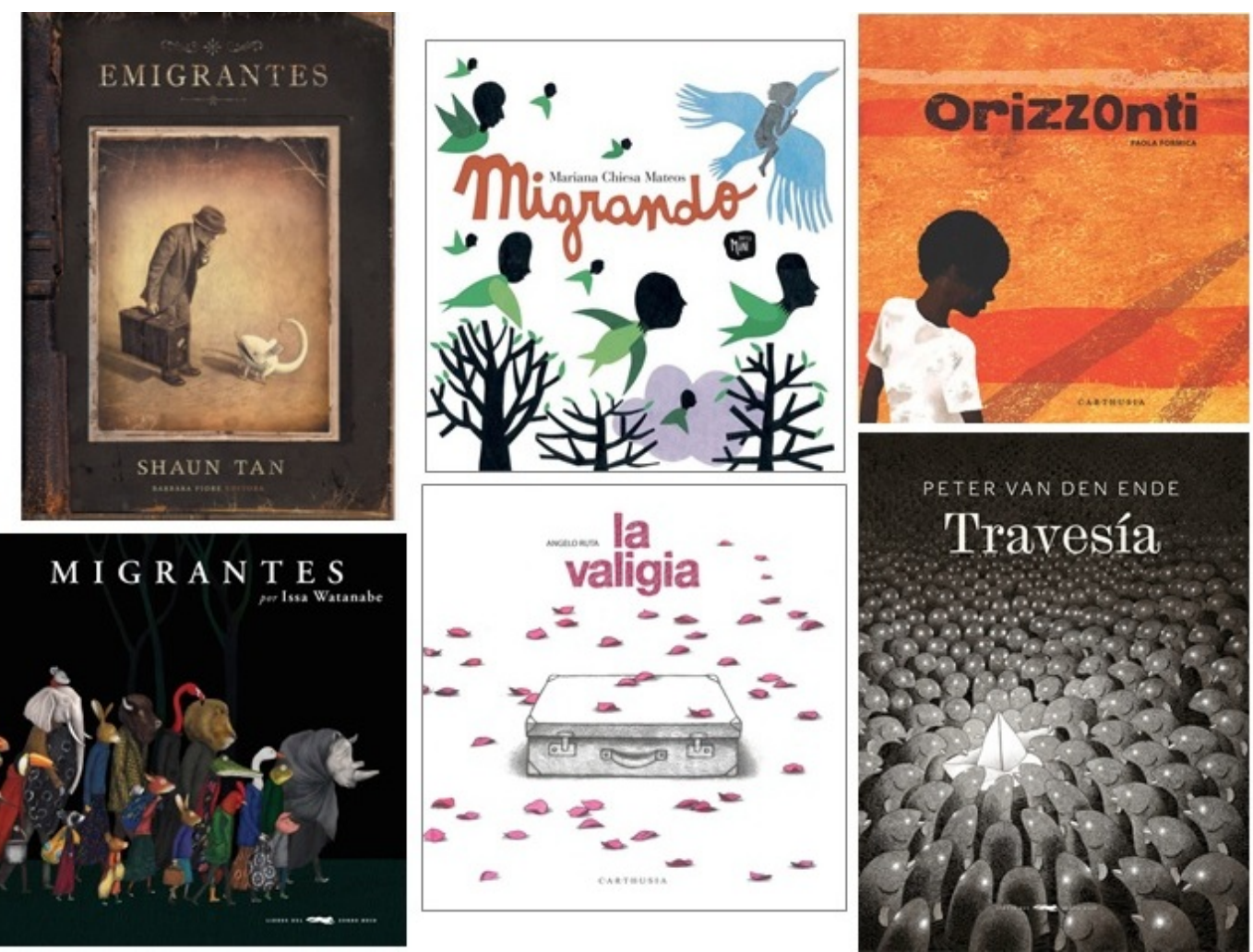

\section{I G R A N T E S}
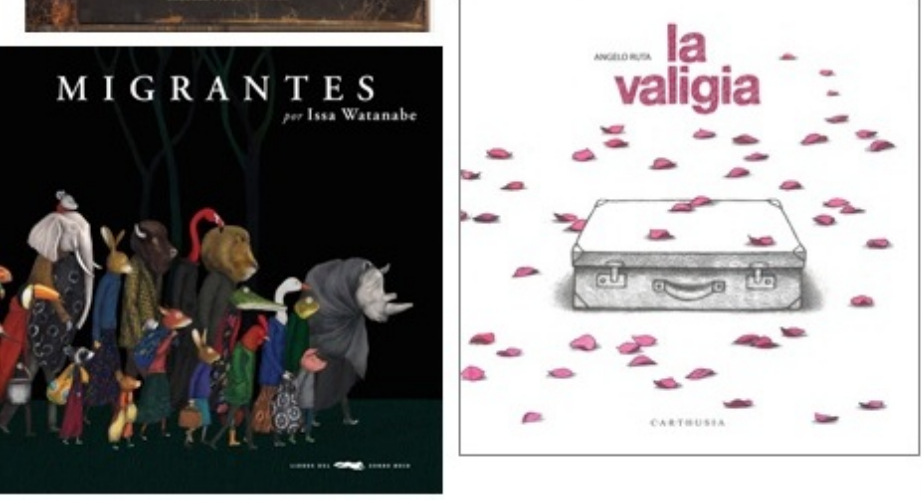

Fuente: propia

\section{NOTAS DE LECTURA}

Las cinco claves o anotaciones que se proponen a continuación pretenden ser orientativas, posibles vías de interpretación dentro de la complejidad que caracteriza a estas obras. Su punto de partida es el análisis de los aspectos de interés en el estudio general de los álbumes sin palabras (Nikolajeva y Scott, 2006; Rowe, 1996): la elocuencia del título y de otros textos peritextuales, la representación de los espacios y del paso del tiempo en la secuenciación narrativa, la función de los personajes y el simbolismo de los significados composicionales y plásticos. Como resultado, se deduce que el discurso no ficcional - aparentemente encubierto, pero latente- se manifiesta a través de unas claves de construcción, cuyo reconocimiento puede estimular experiencias de lectura reflexivas en contextos educativos.

\subsection{La anticipación documental de la cubierta}

En los álbumes sin palabras, los títulos ejercen una función especialmente significativa, al aportar una llave que facilita la orientación de la lectura (Beckett, 2012; Bosch, 2015; Nikolajeva y Scott, 2006; Nodelman, 2000; Rowe, 1996). Además, su relación con la ilustración de la cubierta concretará su sentido y determinará las expectativas del lector -Figura 1-. En este caso, puede observarse cómo los títulos coinciden en la concisión textual y en la abstracción genérica, aspectos que favorecen el distanciamiento ficcional. En primer lugar, la concisión está relacionada con la economía textual que caracteriza estas obras. Desde el título, se evidencia una disposición hacia el 
silencio. El efecto conseguido resulta extremadamente elocuente, al focalizar la atención en una sola palabra. Al mismo tiempo, los términos aluden a conceptos genéricos, incluso la concreción aparente de La valigia contiene un valor simbólico, representativo del viaje. De este modo, los títulos no anuncian referencias espacio-temporales concretas, ni desvelan los nombres de los personajes, como es habitual en los álbumes sin palabras ficcionales que desean personalizar el relato. Cuando en la ilustración de la cubierta se muestra a los personajes solos, los títulos originales The Arrival o de Orizzonti representan una idea sugerente, la llegada o el horizonte, y es la caracterización de los personajes la que aporta el contexto en el que las palabras adquieren un sentido connotativo, vinculado a la experiencia migratoria. Es decir, no se acentúa la singularidad del personaje, sino que el personaje anónimo contribuye a un determinado sentido universal del texto. La colectividad es representada también por la combinación de títulos genéricos e imágenes grupales, como las de Migrantes, Travesía o Migrando. Encontramos así cubiertas que provocan desde el inicio de la lectura una distancia con la narración ficcional, de forma que anticipan un valor próximo al documental o al género denominado docufiction o docuficción.

\subsection{La universalidad espacio-temporal}

Los álbumes sin palabras se estructuran a partir de la imagen secuencial fija (Villafañe y Mínguez, 2017). La carencia de un texto que refiera lo que aconteció entre escenas implica un complejo proceso de selección de las imágenes y montaje de la cadena secuencial. La transformación de los espacios y de los personajes, el orden o la frecuencia con la que aparece una determinada escena generan la sensación del paso del tiempo. A este respecto, en las obras seleccionadas, se observa una intención de universalidad espacial y temporal. La representación del espacio se concreta en referencias comunes que aluden al viaje - Figura 2- en un lugar indeterminado, pues lo que interesa es plasmar una experiencia colectiva y recurrente. En Migrando y en Orizzonti se muestra una valla fronteriza y la huida, en La vagilia, una ciudad destruida por la guerra, y, en la mayoría de las obras, el mar y el barco ocupan varias escenas. Sin embargo, estos espacios no se concretan y se trasciende la idea de internacionalización de la experiencia migratoria. Por otra parte, la concepción plástica de Emigrantes, los tonos sepia, el formato de álbum antiguo y la caracterización de los personajes trasladan a un tiempo pasado la experiencia migratoria; asimismo, Migrando contrasta el pasado y el presente a través de una obra con dos cubiertas distintas y dos historias paralelas que recuerdan que hubo otro tiempo en el que también lo europeos emigraron huyendo del hambre y de la guerra. De este modo, en los dos álbumes, se proyecta la idea de que la experiencia es reiterativa y temporalmente universal. Finalmente, Travesía es la única obra de la selección que no alude de forma directa al viaje migratorio, sino al viaje fantástico y a la aventura a la que se enfrenta un pequeño barco de papel. Las espectaculares imágenes del fondo del mar recrean paisajes fabulosos y oníricos que evocan a Emigrantes, la relación intertextual o intericónica es evidente entre las dos novelas gráficas, dos visiones diferenciadas del viaje, pero conectadas en su propuesta estética, plástica y metafórica. 
Figura 2

Representación de lugares comunes e indeterminado
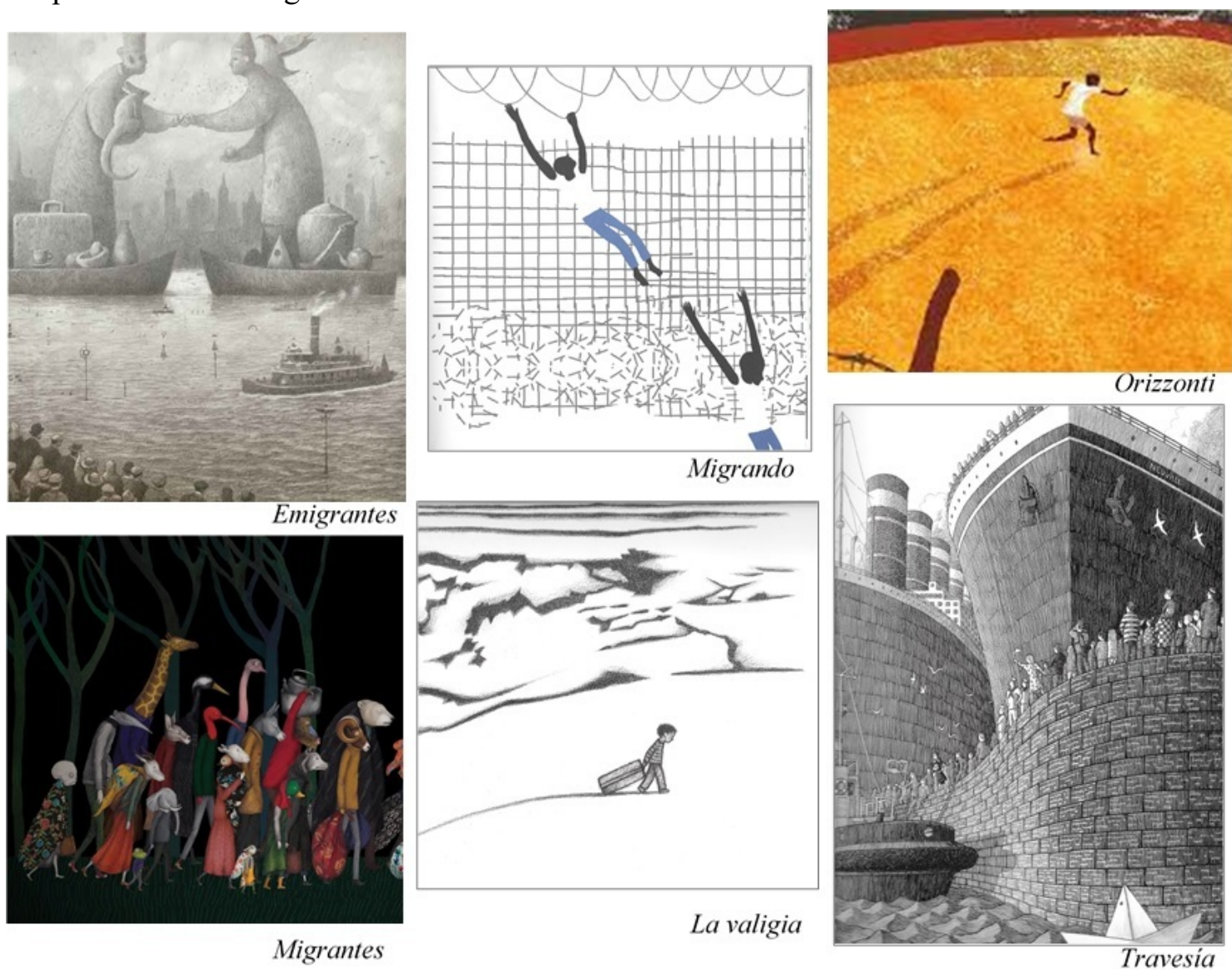

Fuente: propia

\subsection{El personaje colectivo}

Observamos en la selección una tendencia a la escenificación de personajes colectivos. En Emigrantes, Migrantes, Migrando, Orizzonti y Travesía, las imágenes grupales son frecuentes, incluso cuando existe un personaje principal como hilo conductor de la narración. Así, en Emigrantes, la historia familiar y la experiencia migratoria del personaje protagonista se entrecruza con escenas grupales que, a modo de crónica fotográfica, captan el testimonio histórico de las migraciones de principios del siglo XX. En Migrantes, los personajes caminan abatidos en grupo, el lector los contempla desde la distancia, a través de planos generales y un ángulo de visión lateral. En Migrando, se observan barcos repletos de personas y grupos de aves migratorias simbolizan su travesía. Pero la colectividad también se encuentra representada en los personajes unitarios. Por ejemplo, en el caso de La vagilia, el único personaje protagonista es un niño, lo que parece reclamar la identificación y la empatía del lector, al tiempo que el anonimato supone el reflejo de cualquier niño víctima de la guerra. De hecho, las escenas de Travesía, Emigrantes, Orizzonti o Migrando en las que solo aparece un personaje, no se individualiza, sino que contribuye a intensificar el sentimiento de soledad que también conlleva el viaje. De esta forma, desde el título, se evita la denominación distintiva de los personajes, no se conocen sus nombres, pero en las 
ilustraciones se acentúa su mirada, sus rasgos o sus gestos, en la medida en que se tratan de mostrar las emociones comunes provocadas por la experiencia -Figura 3-. Por último, es destacable también la utilización de personajes animales humanizados en Migrantes, Migrando y Travesía. Como señala Tabernero-Sala (2013), cuando se tratan temas trascendentales, los animales generan un efecto distanciador que facilita el discurso infantil. Así, la autora de Migrantes, Issa Watanabe (2020, 27 de febrero), dice utilizar los animales para dotar de cierta fantasía a la historia, puesto que no olvida que se dirige a niños.

Figura 3

El personaje colectivo
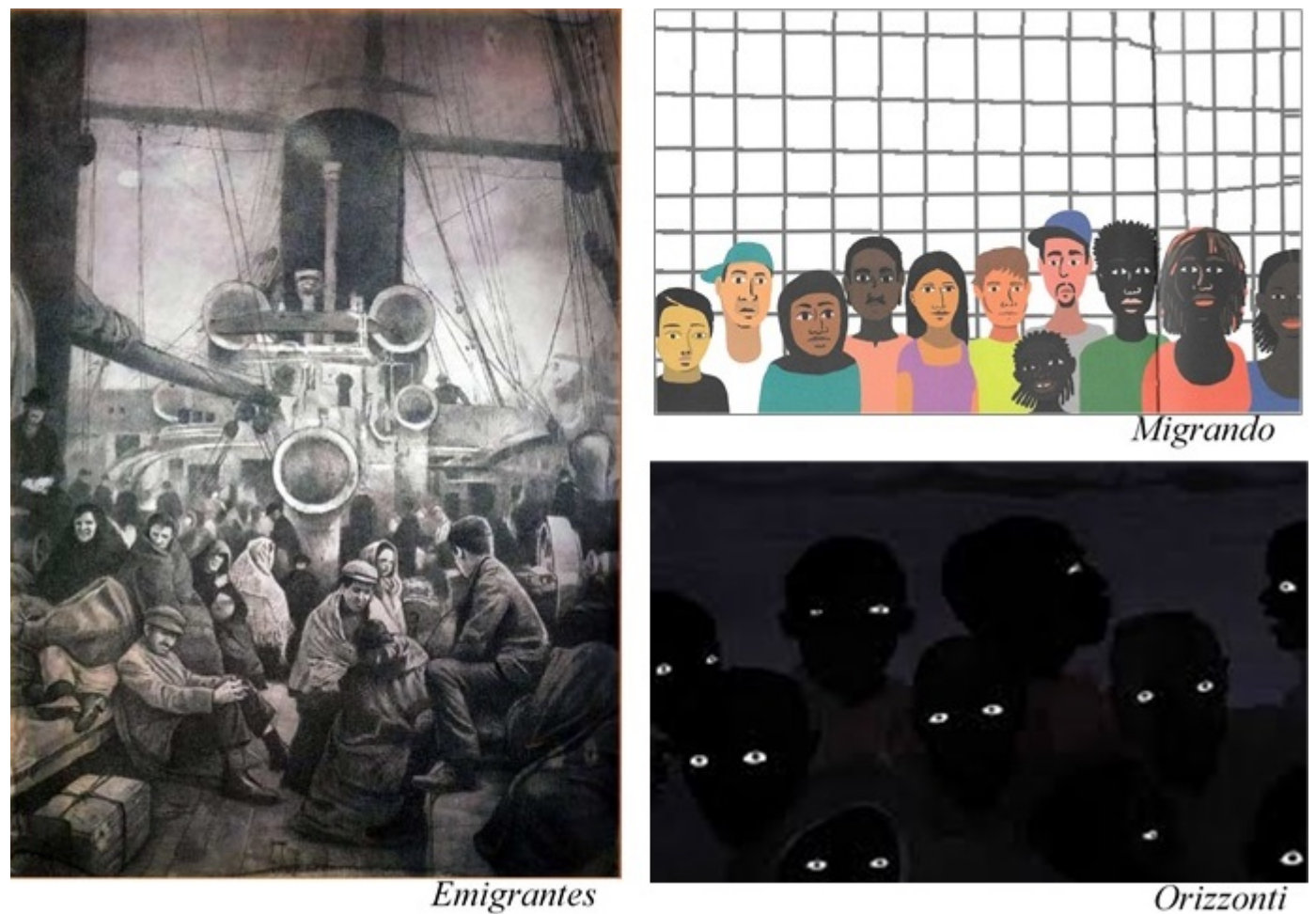

Fuente: propia

\subsection{La voz en off}

Los álbumes sin palabras suelen contener textos editoriales en la contracubierta o en las páginas iniciales o finales, además, también pueden incluir presentaciones de los autores, citas y otros peritextos verbales. Con frecuencia, estos textos suelen dirigir la lectura con preguntas que guían al lector o claves de interpretación, incluso son habituales las referencias a la ausencia de palabras. En la experiencia de lectura, esta escritura funciona como una voz en off (Rowe, 1996). Mientras los personajes están silenciados y el lector contempla su historia en imágenes, una voz de autoría resuena a modo de presentación o cierre del relato, como es propio de los documentales y otros géneros de no ficción. Por ejemplo, en la contracubierta de Emigrantes y Migrantes se interpela al lector a través de preguntas: “¿Qué es lo que lleva a tanta gente a dejarlo todo atrás para viajar hacia un país desconocido (...)” (Tan, 2007); ¿Cuántas fronteras se han de cruzar para llegar a casa?" (Watanabe, 2019). De nuevo, las referencias son colectivas y el 
enfoque de la migración es universal. En este sentido, las citas también son relevantes, por ejemplo, Travesía incorpora una breve reseña de Shaun Tan, la presidenta de Amnistía Internacional en Italia presenta Migrando, y Migrantes utiliza un texto de Theo Angelopoulos. Estas referencias se dirigen especialmente al adulto mediador, quien establecerá un vínculo entre los significados que atribuye a esta autoría y su interpretación de la obra. Asimismo, se destaca el testimonio de la autora de Migrando, Mariana Chiesa, en el que relata la experiencia migratoria de su familia. La autora identifica con nombres propios a sus familiares y personaliza los hechos, pero cierra su texto con una abstracción de la experiencia. Finalmente, resultan significativas las manifestaciones sobre la ausencia de texto, especialmente las realizadas por la editorial Carthusia, promotora del premio internacional Silent Book Contest. En sus publicaciones incluye reflexiones metaliterarias sobre la concepción de los álbumes sin palabras, lo que supone otra estrategia de distanciamiento con la ficción.

\subsection{La abstracción conceptual}

Las ilustraciones son representaciones icónicas con una significación plástica (Villafañe y Mínguez, 2017). La composición de la imagen, los aspectos formales, como el color, o el grado de mímesis de los sujetos representados con la realidad aportan significados semánticos, simbólicos y connotativos a las ilustraciones. Los creadores generan así un determinado ambiente o provocan diferentes niveles de abstracción. En este sentido, se detectan, en las obras comentadas, decisiones creativas en cuanto al color o a la selección de determinados objetos simbólicos que configuran tendencias convergentes. Por ejemplo, la maleta, el barco, las aves o el mar son utilizados por su valor connotativo y representativo del viaje; el color negro, los tonos neutros o la escala de grises se muestran recurrentes en la expresión de austeridad, dureza, sobriedad o tristeza. De este modo, los autores consiguen representar imágenes que tratan de fotografiar la realidad para reforzar su significado, imágenes metafóricas o alegóricas, e imágenes que combinan ambos planteamientos. Por ejemplo, Migrando utiliza las aves migratorias como metáfora; en Orizzonti, una caracola evoca las voces de los que han muerto en el mar; la muerte es representada igualmente en Migrantes como un personaje que acompaña al grupo en su viaje; la maleta de La valigia es un refugio que conserva los recuerdos felices y familiares de una vida anterior a la guerra; mientras que en Emigrantes y en la Travesía las imágenes oníricas presentan un mayor grado de ambigüedad que requiere de la interpretación personal del lector -Figura 4-. Mediante estos recursos, se consiguen abstraer las experiencias de los personajes a un nivel genérico, reflexivo y conceptual. En este sentido, destaca la obra Travesía, pues en ella no se muestran referencias directas al viaje migratorio, sino que el viaje adquiere aquí mayor nivel de abstracción. Así, la travesía de un barco de papel, frágil pero resistente a las adversidades, logra un sentido alegórico sobre el devenir de la vida y conecta con un tópico tradicional de la literatura, un espejo en el que cada lector puede ver reflejadas sus experiencias, un espacio acogedor también para la experiencia migratoria, en tanto que se invita a los lectores a la construcción de sentido de esta propuesta. 
Figura 4

Símbolos y metáforas visuales
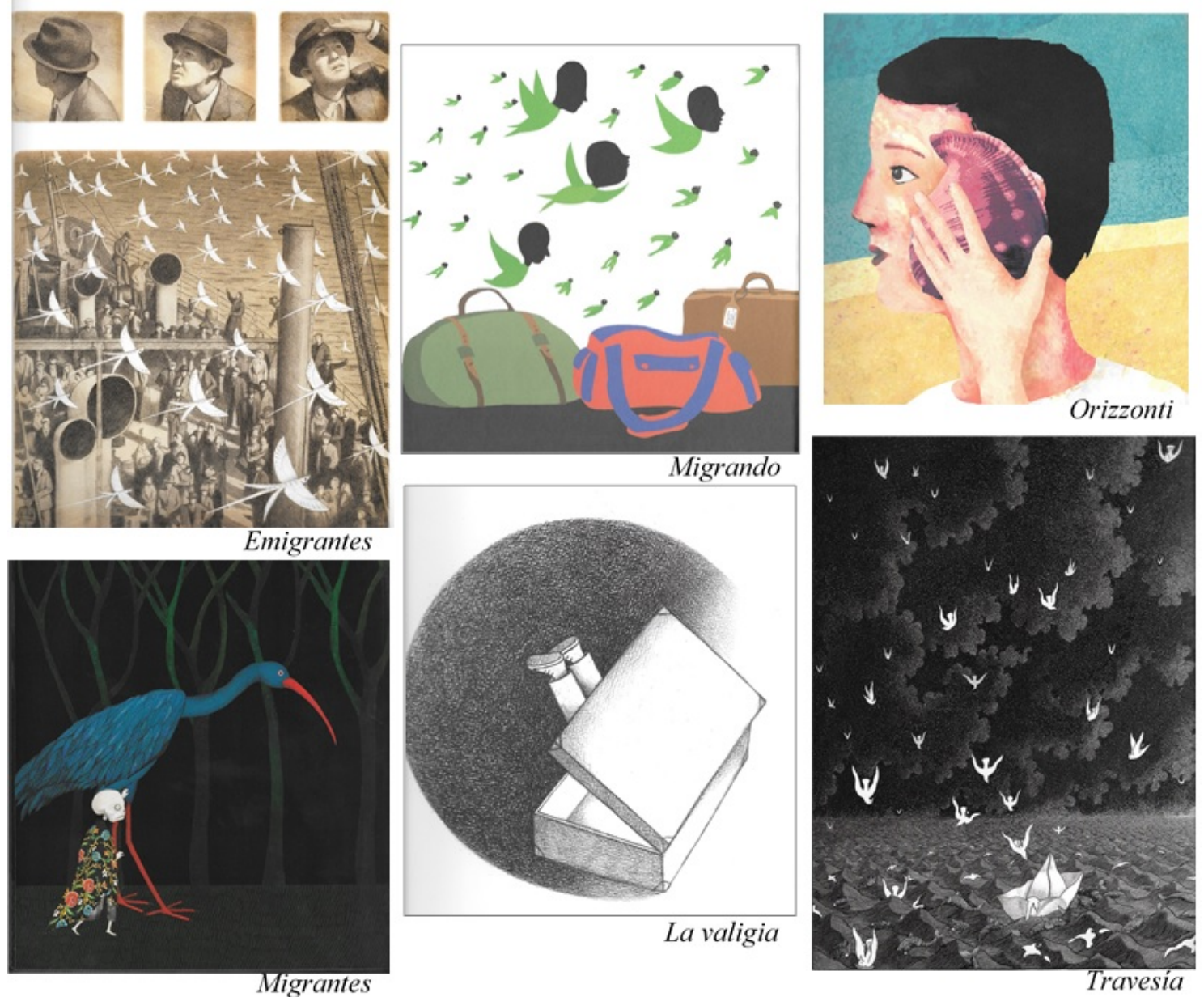

Fuente: propia

\section{CONCLUSIONES}

Los álbumes sin palabras, aunque de naturaleza especialmente visual (Bosch, 2015; Nikolajeva y Scott, 2006), se conforman como textos multimodales (Serafini, 2014) potencialmente adecuados para la alfabetización visual, la educación literaria y artística, el desarrollo de estrategias lectoras y el aprendizaje significativo (Rita-Gomes, 2012), según apuntan los resultados de las investigaciones empíricas sobre su recepción (Arizpe et al., 2015; Colón y Tabernero-Sala, 2018; Iordanaki, 2017; Lysaker, 2019; Mantei y Kervin, 2015). Sin embargo, dada su singularidad (Lartitegui, 2014; Van der Linden, 2015), parecen generar cierta desconfianza en el mediador, quien declara que carece de estrategias para su integración en los programas educativos (Skubic y Podobnik, 2018). Desde esta premisa, el estudio realizado tenía como objetivo aportar unas orientaciones o claves de aproximación a una selección de álbumes sin palabras, caracterizados por abordar un tema complejo y controvertido de interés educativo, el fenómeno migratorio.

En su ensayo sobre la cultura visual, Mirzoeff (2003) sostiene que los medios visuales, cuando se manejan bien, poseen una gran capacidad para tratar cuestiones morales complejas. De hecho, cuando los autores de libros infantiles optan por 
narraciones sin palabras para plantear temas comprometidos, el silencio contribuye a crear una experiencia de lectura singular y compleja, en la que las ilustraciones cobran mayor fuerza, pues la imagen fija, que no cuenta con el anclaje del texto, necesita una contemplación sosegada e introspectiva que difícilmente se puede conceder a la imagen en movimiento. En las obras seleccionadas, se observa además cómo la economía textual contribuye a dotar de un carácter documental y universal al relato. De este modo, los autores utilizan la narración ficcional como soporte (Sampériz et al., 2021) de un discurso no ficcional implícito. En este sentido, resultan de interés las reflexiones de Shaun Tan (2017) sobre su obra Emigrantes:

(...) los detalles sobre el día a día fueron los que me parecieron más elocuentes y los que me sugirieron experiencias humanas más comunes y universales. Me recordaron que las migraciones son partes fundamentales de la historia de la humanidad, tanto en la antigüedad como en un pasado más reciente. (párr. 8).

(...) en su ausencia [en referencia a las palabras], una imagen puede gozar a menudo de más espacio conceptual a su alrededor, como también puede invitar al lector a prestar atención con más detenimiento (...). (párr. 10).

Para comprender mejor en qué consiste viajar a un país nuevo, quise crear un lugar de ficción que resultara extraño para los lectores de cualquier edad o procedencia (incluyéndome a mí mismo). (párr. 16).

Las declaraciones de Shaun Tan (2017) sobre su proceso creativo manifiestan una concepción universal de la experiencia migratoria y la utilización de la ficción como recurso para implicar al lector. Se detecta, así, cómo los autores recurren a la ficción al mismo tiempo que parecen distanciarse de elementos propios de la ficción, como la singularidad de los personajes, la originalidad de la historia o una ubicación espaciotemporal que genere un efecto ilusorio de realidad. En este caso, los autores comparten la misma historia, los mismos personajes y los mismos lugares comunes porque es la mirada personal, artística y creativa del autor la que aporta singularidad a cada uno de los álbumes. En consecuencia, el discurso no ficcional propicia una abstracción conceptual sobre el viaje y la experiencia migratoria a través de personajes anónimos y colectivos, títulos genéricos, voces de autoría en off que incitan a la reflexión, imágenes simbólicas y metafóricas, espacios comunes pero indeterminados o referencias temporales que asemejan el pasado y el presente como ciclo recurrente de la historia.

Esta interpretación discursiva supondría un contrapunto a las interpretaciones sociales e ideológicas de estos álbumes (Arizpe et al., 2015; Nel, 2018; Pesonen, 2020), puesto que una lectura crítica y creativa debería contemplar diferentes perspectivas. Pesonen (2020), por ejemplo, se preguntaba cómo una obra sin texto podía reflejar la experiencia de las personas migrantes al tiempo que consideraba que este tipo de obras solían trasladar una mirada uniforme y homogénea de ellas. Desde el análisis expuesto, cabría decir que la renuncia a la palabra en favor de la elocuencia de las imágenes es una actitud contenida ante situaciones en las que los autores desean mostrar con imágenes su mirada personal, creativa y también adulta (Nodelman, 2020) del mundo, una invitación a la voz de los lectores infantiles (y adultos), a la observación detenida y a la reflexión sobre una experiencia colectiva y universal que implica a toda la humanidad. 


\section{NOTAS}

1 Esta investigación forma parte del Proyecto I+D+i Formar lectores en la sociedad digital desde el libro de no ficción (RTI2018-093825-B-I00) (Ministerio de Ciencia, Innovación y Universidades. Gobierno de España)

\section{FINANCIACIÓN}

Esta investigación fue financiada por el Ministerio de Ciencia, Innovación y Universidades de España, cuyo número de referencia del proyecto es RTI2018-093825B-I00.

\section{REFERENCIAS BIBLIOGRÁFICAS}

Arizpe, E., Colomer, T., y Martínez-Roldán, C. (2015). Visual journeys through wordless narratives: An international inquiry with immigrant children and 'The Arrival'. Bloomsbury.

Bader, B. (1976). American picturebooks from Noah's ark to The beast within. Macmillan Publishing.

Beckett, S. L. (2012). Wordless picturebooks. En S.L. Beckett, Crossover picturebooks: A genre for all ages (pp. 81-145). Routledge.

Bosch, E. (2015). Estudio del álbum sin palabras [Tesis doctoral]. Universitat de Barcelona. https://bit.ly/34Gdg4Q

Chiesa-Mateos, M. (2010). Migrando. Orecchio Acerbo.

Colón, M. J., y Tabernero-Sala, R. (2018). El álbum sin palabras y la construcción de una comunidad lectora en la biblioteca pública. Ocnos. Revista de Estudios sobre Lectura, 17(3), 31-41. https://doi.org/10.18239/ocnos_2018.17.3.1796

Costa, I., y Ramos, A.M. (2021). Literatura sin palabras: el caso de los libros-álbum sin texto. Acta Poética, 42(1), 69-86. https://doi.org/10.19130/1ifl.ap.2021.1.886

Ducrot, V. (2014). L'album muet: Une esquisse de textes dissimulés. Le français aujourd'hui, 186(3), 66-74. https://doi.org/10.3917/1fa.186.0066

Eisner, E. W. (2020). El arte y la creación de la mente. El papel de las artes visuales en la transformación de la conciencia. Paidós.

Formica, P. (2015). Orizzonti. Carthusia.

Genette, G. (2001). Umbrales. Siglo XXI.

Grande-López, V. (2018). Ver mundos diferentes estimula la imaginación. Hachetetepé. Revista científica de Educación y Comunicación, (17), 71-81. https://doi.org/10.25267/Hachetetepe.2018.v2.i17.8

Iordanaki, E. (2017). A socio-cultural study exploring Greek and English 11-year-old children's responses to wordless picturebooks [Tesis doctoral, University of Cambridge]. https://doi.org/10.17863/CAM.13912

Kümmerling-Meibauer, B. (2015). From baby books to picturebooks for adults: European picturebooks in the new millennium. Word \& Image, 31(3), 249-264. https://doi.org/10.1080/02666286.2015.1032519

Lartitegui, A. G. (2014). Páginas mudas, libros elocuentes: Tramas visuales y discurso. Pantalia.

Lartitegui, A.G. (2018). Alfabeto del libro de conocimientos. Paradigmas de una nueva era. Pantalia.

Lewis, D. (2001). Reading contemporary picturebooks: Picturing text. Routledge. 
Lysaker, J. T. (2019). Before words. Wordless picture books and the development of reading in young children. Teachers College Press.

Mantei, J., y Kervin, L.K. (2015). Examining the interpretations children share from their reading of an almost wordless picture book during independent reading time. Australian Journal of Language and Literacy, 38(3), 183-192. https://bit.ly/3vPwS2c

Mirzoeff, N. (2003). Una introducción a la cultura visual. Paidós.

Nel, P. (2018). Introduction: Migration, refugees, and diaspora in children's Literature. Children's Literature Association Quarterly, 43(4), 357-362. https://doi.org/10.1353/chq.2018.0043

Nikolajeva, M., y Scott, C. (2006). How picturebooks work. Routledge.

Nodelman, P. (2000). Words about pictures. The narrative art of children's picture books. The University of Georgia Press.

Nodelman, P. (2010). Las narrativas de los libros-álbum y el proyecto de la literatura infantil. En T. Colomer, B. Kümmerling-Meibauer y M. C. Silva-Díaz (Eds.), Cruce de miradas: Nuevas aproximaciones al libro-álbum (pp. 18-33). Banco del Libro - Gretel.

Nodelman, P. (2020). El adulto escondido. Definiendo la literatura infantil y juvenil. Pantalia.

Pesonen, J. (2020). 'Meidän piti lähteä' and the problematics of voicing the refugee experience in a wordless picturebook. Barnboken, 43, 1-18. https://doi.org/10.14811/clr.v43i0.485

Rita-Gomes, V. (2012). Lectura de imagen y aprendizaje significativo. Hachetetepé. Revista científica de Educación y Comunicación, (4), 137-146. https://doi.org/10.25267/Hachetetepe.2012.v1.i4.12

Romero-Oliva, M.F., Heredia-Ponce, H., y Sampériz-Hernández, M. (2019). El booktrailer como herramienta digital en la formación lectora de los futuros docentes. Un estudio de caso. Caracteres. Estudios culturales y críticos de la esfera digital, 8(2), 92-128. https://bit.ly/3caf7Ti

Rowe, A. (1996). Reading Wordless Picture Books. En M. Styles, E. Bearne y V. Watson (Eds.), Voices Off: Texts, Contexts and Readers (pp. 219-234). Cassell.

Ruta, A. (2019). La valigia. Carthusia.

Sampériz, M., Tabernero, R., Colón, M.J., y Manrique, N. (2021). El libro de no fícción para prelectores. Análisis de las claves de construcción del discurso. Cuaderno. Centro de Estudios en Diseño y Comunicación, 124, 73-90. https://doi.org/10.18682/cdc.vi124

Serafini, F. (2014). Reading the visual: An introduction to teaching multimodal literacy. Teachers College Press.

Sipe, L. R., y Pantaleo, S. (Eds.). (2008). Postmodern picturebooks: Play, parody, and self-referentiality. Routledge.

Skubic, D., y Podobnik, U. (2018). Preschool teachers' beliefs about the use of wordless picture books in kindergarten. Jezik in Slovstvo, 63(4), 17-31. https://bit.ly/3vJg6BK

Tabernero Sala, R., Álvarez Ramos, E., y Heredia Ponce, H. (2020). Hábitos de lectura y consumo de información de los adolescentes en el ámbito digital. Investigaciones Sobre Lectura, (13), 90-107. https://doi.org/10.37132/isl.v0i13.302 
Tabernero-Sala, R. (2005). Nuevas y viejas formas de contar: El discurso narrativo infantil en los umbrales del siglo XXI. Prensas Universitarias de Zaragoza.

Tabernero-Sala, R. (2013). El lector literario en los grados de maestro: deconstruir para construir. Lenguaje y textos, 38, 47-56. https://bit.ly/3cf4ZZM

Tabernero-Sala, R. (2016). Los epitextos virtuales en la difusión del libro infantil: Hacia una poética del book-trailer. Un modelo de análisis. Ocnos. Revista de Estudios sobre Lectura, 15(2), 21-36. https://doi.org/10.18239/ocnos_2016.15.2.1125

Tan, S. (2007). Emigrantes. Barbara Fiore.

Tan, S. (2017). Emigrantes. Página oficial de la editorial Barbara Fiore. https://bit.ly/2TqIZEv

Terrusi, M. (2017). Meraviglie mute. Silent book e letteratura per l'infanzia. Carocci editore.

Tomasi, S. (2014). La voz secreta de la ilustración: Una propuesta para la educación de la imagen. Hachetepepe. Revista científica de Educación y Comunicación, (8), 24-42. https://dx.doi.org/10.25267/Hachetetepe.2014.v1.i8.4

Trigo Ibáñez, E., Santos Díaz, I.C., y Sánchez Rodríguez, S. (2020). ¿Qué leen los adolescentes españoles? Un estudio de los consumos de lectura analógica. Investigaciones Sobre Lectura, (13), 54-71. https://doi.org/10.37132/isl.v0i13.278

Valencia-Leguizamón, M., y Real, N. (2019). Libro álbum y formación básica docente. Un estudio de caso en la Universidad de Quindío. Bellaterra Journal of Teaching \& Learning Language \& Literature, 12(3), 65-90. https://doi.org/10.5565/rev/jt13.847

Van den Ende, P. (2020). Travesía. Libros del Zorro Rojo.

Van der Linden, S. (2015). Álbum [es]. Ekaré.

Villafañe, J., y Mínguez, N. (2017). Principios de Teoría General de la Imagen. Pirámide. Watanabe, I. (2019). Migrantes. Libros del Zorro Rojo.

Watanabe, I. (2020, 27 de febrero). Así narra la ilustradora Issa Watanabe su obra 'Migrantes'. La Vanguardia. https://bit.ly/3icg6Gs

Zizioli, E. (2017). I tesoro della lettura sull'isola. Una pratica di cittadinanza posible. Sinnos. 